\title{
BOXED TEXTS
}

I. The Erfurt Declaration-2008 / 8

2. Restoration of Mousam Lake / 40

3. Building in Agricultural Areas: Harmony, Florida / 43

4. Habitat Selection: A Bird's-Eye View / 46

5. Urban Stopover Sites for Migrating Birds / 48

6. Corridors, Birds, and Plant Diversity / 52

7. Compact versus Fragmented Subdivision / 55

8. Keeping the Working Land Working / 58

9. Aurora Development Construction Covenants, Whittlesea, Australia / 60

IO. Prescribed Fire and Neighborhoods / 68

II. Open Space Subdivisions Policy / 71

12. Harmony Community Development District / 73

13. Washington Biodiversity Project / 77

14. Having a Conversation with Neighbors / 81

15. Lake Okareka Walkway, Rotorua, New Zealand / 85

16. BioBlitz, Connecticut Style / 88

17. The Case for Snags / 99

I8. Prairie Crossing Development, Illinois / 104

19. The Precautionary Principle and Pesticide Use in Quebec / 109 
20. Stormwater Treatment Train and LID / 119

2I. Alternative Natural Landscaping Saves on Infrastructure Cost / 125

22. Irrigation and Soil Moisture Sensors / 128

23. Seattle's Street Edge Alternatives Project / 131

24. Landscaping and Irrigation Ordinance, Pasco County, Florida / 134

25. Harmony's Dark Sky Project / 141

26. CC\&Rs in Phoenix, Arizona / 147

27. Wildlife Friendly Development Certification, North Carolina / 155

28. The Woodlands at Davidson, North Carolina / 169 